\title{
Motivational Interviewing for Smoking Cessation and Increase of Physical Activity in Adults
}

\author{
Despoina Leontari ${ }^{1,2 *}$, Vasiliki Zisi², Stamatia Gratsani ${ }^{1,2}$, Styliani Chroni ${ }^{3}$, Yannis Theodorakis ${ }^{2}$ \\ ${ }^{1}$ Mobile Mental Health Unit, Trikala, Greece \\ ${ }^{2}$ Department of Physical Education \& Sport Science, University of Thessaly, Trikala, Greece \\ ${ }^{3}$ Department of Sports \& Physical Education, Hedmark University College, Terningen Arena, Hamarveien, Elverum, \\ Norway \\ Email: *despoinaleontari@gmail.com
}

How to cite this paper: Leontari, D., Zisi, V., Gratsani, S., Chroni, S., \& Theodorakis, Y. (2017). Motivational Interviewing for Smoking Cessation and Increase of Physical Activity in Adults. Psychology, 8, 1988-2010. https://doi.org/10.4236/psych.2017.812127

Received: September 1, 2017

Accepted: October 17, 2017

Published: October 20, 2017

Copyright $\odot 2017$ by authors and Scientific Research Publishing Inc. This work is licensed under the Creative Commons Attribution International License (CC BY 4.0).

http://creativecommons.org/licenses/by/4.0/

\begin{abstract}
This study investigated if and how an individual counselling program, based on motivational interviewing, affects lifestyle changes that contribute to smoking cessation and physical activity enhancement. The participants were 2 men and 6 women aged 25 - 54 years. The program consisted of 12 individual weekly counselling sessions based on motivational interviewing. There was a 9 month follow up (monthly sessions, weekly telephone calls). A semi-structured interview was used to evaluate the effectiveness of the program after the intervention. Qualitative content analysis was used, along with the In Vivo Software in organizing the data from the interview. At the end of the follow up, three participants stopped smoking, four participants turned to light smokers $(<10$ cigarettes per day) and only one person failed to change smoking behavior. The participants reported that the discussion and communication with the advisor were very helpful, such as the support, the commitment, the resistance and the goal setting techniques. The gains that the participants experienced were a general life-style change, smoking cessation or smoking reduction, motivation, sensitization, self-esteem, self-knowledge, safeness, stress reduction, relaxation and better physical condition. It seems that motivational interviewing greatly contributes to helping adults to quit or reduce smoking and adopt a healthier lifestyle.
\end{abstract}

\section{Keywords}

Smoking, Physical Activity, Counselling, Transtheoretical Model, Motivational Interviewing 


\section{Introduction}

Smoking, for many people, is associated with enjoyment, but provided evidence indicates it as a disastrous habit. According to the World Health Organization (2016), about 1.1 billion people-one in every three adults-are smokers. Tobacco kills about 6 million people each year and will have killed about 8 million by the year 2025; more than 5 million of those deaths are the result of direct tobacco use, while more than 600 thousands are the result of non-smokers being exposed to second-hand smoke (World Health Organization, 2016). Nicotine addiction is viewed nowadays, more of a psychological than a physical dependency, since smoking has been classified in addictions (F17.2 nicotine; tobacco; dependence) in the International Classification of Diseases- $10^{\text {th }}$ Revision (ICD-10, World Health Organization, 2015). Several types of psychological techniques have been developed thus, aiming in increasing the effectiveness of smoking cessation interventions.

Counselling holds a central role in interventions aiming in changing health behaviors and it seems that interventions based on counselling, are effective in smoking cessation, either they are short or intensive, combined with other treatment or not (Zisi, Gratsani, Leontari, \& Theodorakis, 2016). Even brief counselling cessations have been proved to improve abstinence rates of up to $2.5 \%$ as opposed to no counselling at all (Shah, Rao, \& Mayo, 2008), to increase the rates of smoking cessation, and to also raise the smokers' mobilization and their chances to enter a cessation process (Pisinger, Vestbo, Borch-Johnsen, Thomsen, \& Jorgensen, 2005). Several researchers employed the idea of combining counselling with other interventions, such as pharmaceuticals (e.g. bupropion or other nicotine preparations) believing they can further increase its effectiveness. It seems however, that this combination does not change, does not increase and does not alter the effects of counselling as a sole treatment (Hall et al., 2011). Nevertheless, when each of the combined interventions was implemented by experts-for example counselling from mental health specialists, medication by medical staff, intervention for oral hygiene by dentists, motivation to abstain from smoking seemed to increase (Gonseth, Abarca, Madrid, \& Cornuz, 2010).

The main goal of individual counselling is to challenge thoughts and feelings for which the individual had not been fully aware by then, aiming to help the person develop and solve the problems of worry, such as smoking. Counselling seems to play a pivotal role in increasing confidence for a successful smoking cessation, in protecting against guilt issues after relapse, and in reducing perceived difficulties in smoking cessation efforts (McCarthy et al., 2010). Researchers' interest turned to a number of factors linked with counselling, such as the conditions and the period of time that could make smokers more vulnerable or more ready to enter a switching process. Interventions implemented in hospitals under the assumption that the patients may be more vulnerable, open and ready to quit smoking at that time, proved to be more effective (Rigotti, Munafo, 
\& Stead, 2008) as the majority of the participants (75\%) indicated readiness in quitting smoking. After being advised on smoking cessation, they exhibited increased successful effort probabilities and abstinence maintenance (Shah et al., 2010; Rigotti, Regan, Majchrzak, Knight, \& Wechsler, 2002). However, the effectiveness of these interventions has suffered dispute by researchers who claimed that differences in quit rates are not significant (Hennrikus et al., 2005; Hjalmarson \& Boethius, 2007). As for the time appropriateness, it has been argued that the use of counselling immediately after the day of stop smoking on a daily basis (Front-Loaded Counselling) can ensure greater abstinence and reduce chances of relapse a year later, as opposed to the use of counselling on a weekly basis throughout the participants quit effort (Garvey et al., 2012).

Several intervention programs based on psychological support, focused on certain factors, such as motivation, self-efficacy and social support relations, since they appear to affect the smoking cessation attempt (Johnston, Johnston, Pollard, Kinmonth, \& Mant, 2004; Norman, Conner, \& Bell, 1999; Hassandra, Goudas, \& Theodorakis, 2015), and also because the need for emotional coverage appears to be a very important reason for smoking (Singleton \& Pope, 2000). In addition, the use of awards was found to play an important role in increasing engagement and commitment to treatment rates, and in smoking abstinence as compared to standard cognitive-behavioral therapy (Hunt, Rash, Burke, \& Parker, 2010).

Feedback for health risks was not found to influence the smokers' motivation to use more often the treatment services, to quit and to abstain from smoking (McClure, Ludman, Grothaus, Pabiniak, \& Richards, 2009). Smokers do not seem to worry about the effects that smoking has on their health but they are worried about the consequences smoking has on others (passive smoking, Schane, Prochaska, \& Glantz, 2013). The way the information is provided seems to be important and Motivational Interviewing appeared to be more effective than simple direct cessation advices (Gemmell \& DiClemente, 2009).

Apart from the effectiveness of counselling on the smoking cessation process, physical activity has been proved to be a key part in the smoking cessation effort. Surveys suggested that the more people exercise the less they smoke (Marti, Salonen, Tuomilehto, \& Pulska, 1988; Salonen, Slater, Tuomilehto, \& Raurama, 1988; Tuomilehto et al., 1987). It was also found that exercisers can limit and stop smoking more easily than non-exercisers (Godin, 1989; Boudreaux, Francis, Taylor, Scarinci, \& Brantley, 2003; Hassandra et al., 2015). Exercise is now recognized as a low cost factor of prevention and smoking cessation and can be used both for smoking prevention and for smoking cessation. However, preventive programs should focus on an overall healthy lifestyle, including exercise, rather than on smoking solely. Moreover, long-term interventions which employ exercise as a means of stop smoking should be coupled with respective counselling strategies (Hassandra et al., 2015).

Among the studies carried out in the area of smoking cessation, interventions 
based on the theory of Motivational Interviewing (MI, Miller \& Rollnick, 2002) have been proved of high effectiveness. MI refers to a kind of person-centred counselling, which aims to increase the individual's motivation to change, enhance self-efficacy and provide guidance to understand the problematic behavior, without any pressure for change from the advisor. It is a short psychotherapeutic intervention designed to increase the likelihood of a person to think, to initiate and maintain certain change strategies in order to reduce the problematic behavior. The main objectives of motivational interviewing are to resolve ambivalence, which is considered the main obstacle to the inception of the change process, to increase motivation and to facilitate change. Motivation to change is elicited from within the individual and not imposed from outside (Miller \& Rollnick, 2002). The ambivalence occurs when the person is feeling in two different ways about something or someone and this feeling takes the form of conflict between two possible courses of action; each of them has advantages and disadvantages associated with it. MI is a way of communicating and being with people, a style of counselling and psychotherapy, not a set of techniques. The consultant shall respect the autonomy and freedom of choice of the consulted, who has a prominent role in the whole process (Rollnick \& Miller, 1995; Miller \& Rollnick, 2002).

Many studies have supported the MI approach as particularly helpful, especially in populations suffering from various addictions such as smoking (Butler et al., 1999; Dunn, Deroo, \& Rivara, 2001; Rollnick, Butler, \& Scott, 1997; Rollnick \& Heather, 1992), although most of them are short interventions for adolescents (Erol \& Erdogan, 2008; Colby et al., 2005; Colby et al., 1998). Little is known however, about the application of $\mathrm{MI}$ in smoking cessation programs for adults. So far, very few clinical intervention studies using Adaptive forms of Motivational Interviewing (AMI) have been published (Colby et al., 1998; Butler et al., 1999), and their results favored the intervention of motivational interviewing but no statistically significant differences were reported about important metrics such as the percentage abstinence and cessation efforts.

Due to the lack of studies based on MI for smoking cessation in adults, currently there is not enough evidence to support the effectiveness of these interventions in smoking cessation. The innovation of the current study is the attempt to implement a counselling program for smoking cessation in adult smokers based on MI, trying to identify the specific techniques, features and qualities of the consultation process that help the participants change their way of thinking, so that they may give up smoking and increase their physical activity. The ultimate goal was to bridge the existing knowledge gap in this area, to highlight some key points and to contribute to the construction of more comprehensive intervention programs for smoking cessation.

The aim of this intervention was to study whether and how a counselling program for smoking cessation, based on motivational interviewing, affected the smoking cessation process. The behavior change processes were studied not only in the participants who quit smoking but also in those who decreased smoking at 
a significant rate until the end of the intervention. Whether and how the participants made changes in their daily lives towards a healthier lifestyle was also considered. Taking into account the results of previous research on the effectiveness of counselling on smoking cessation programs, that used similar intervention methodology (i.e. Zisi et al., 2016), it was hypothesized that: a) The intervention program will enhance the smoking cessation effort; $b$ ) the participants who will not succeed in quitting smoking will achieve a significant reduction in the number of cigarettes smoked daily; c) the participants' physical activity will increase; and d) the participants will make substantial changes in everyday life and adopt new behaviors and habits towards a healthier lifestyle and of better quality.

\section{Methods}

\section{Study Criteria and Recruitment}

The study was carried out in Trikala, a town located in central Greece. An advertisement in local print and electronic media invited participants who were interested to give up smoking. A prerequisite for participation in the survey was the intention to reduce or quit smoking and the commitment to participate in the individual counselling intervention program. During the first contact, the participants were orally informed by one of the researchers about the aim of the study, the procedures and the number of visits needed for the completion of the intervention program. They signed a consent form, with which they were informed that questionnaires and transcripts would be anonymized, treated confidentially and that they were free to withdraw at any point during the study, if they so wished. Ethical Approval for the study was obtained by the Ethics Committee of the School of Physical Education and Sport Science, University of Thessaly, Greece (1-1/20-6-2012).

\section{Participants and data collection}

The participants were 8 adults, aged $25-54$ (mean age $=38.5), 2$ men and 6 women. Participants' characteristics are presented on Table 1.

Table 1. Participants' characteristics.

\begin{tabular}{cccccc}
\hline Participants & $\begin{array}{c}\text { Age } \\
(\mathrm{yrs})\end{array}$ & $\begin{array}{c}\text { Years of } \\
\text { smoking }\end{array}$ & $\begin{array}{c}\text { Number of daily } \\
\text { cigarettes before } \\
\text { intervention }\end{array}$ & $\begin{array}{c}\text { Number of daily } \\
\text { cigarettes } \\
\text { after intervention }\end{array}$ & $\begin{array}{c}\text { Number of } \\
\text { cigarettes } \\
\text { at follow up }\end{array}$ \\
\hline $1^{\text {st }}$ participant & 45 & 30 & 25 & 10 & 25 \\
$2^{\text {nd }}$ participant & 29 & 14 & 20 & 0 & 0 \\
$3^{\text {rd }}$ participant & 52 & 34 & 15 & 8 & 8 \\
$4^{\text {th }}$ participant & 31 & 15 & 15 & 7 & 7 \\
$5^{\text {th }}$ participant & 48 & 30 & 15 & 6 & 6 \\
$6^{\text {th }}$ participant & 31 & 15 & 15 & 10 & 10 \\
$7^{\text {th }}$ participant & 35 & 12 & 17 & 0 & 0 \\
$8^{\text {th }}$ participant & 37 & 20 & 25 & 0 & 0
\end{tabular}




\section{Intervention}

The intervention consisted of 12 individual counseling sessions in total. The frequency of the individual sessions was once per week and their duration was one hour. Individual counseling was person-centered and based on the theory of Motivational Interviewing (Miller \& Rollnick, 2002). In each individual counseling session, certain objectives, which the participant should accomplish until the next meeting, were set and discussed. The objectives focused mainly on issues of reducing the number of cigarettes smoked, exercise and diet habits, stress management and time organization.

The framework of the counseling support in total was structured on the basis of five behavioral theories: Social Cognitive theory (Bandura, 1997), theory of Planned Behaviour (Ajzen, 1985; Butler, 2001), Goal Setting theory (Locke \& Latham, 1990), Health "Believe" model (Rosenstock, 1974) and Transtheoretical model (Prochaska \& Diclemente, 1983). Each counseling session was aiming on certain topics, for example cognitive awareness on issues related to smoking, exploring the reasons of smoking and discussing the possible ways to quit, debate on beliefs about smoking, attitudes and unhealthy behaviors, discussion about the concerns of quitting, positive reframing of past efforts, enhancing self-confidence and self-awareness, stress management, relaxation and visualization techniques, the benefits of exercise on smoking cessation process, techniques to overcome the desire to smoke and addiction symptoms, self-talk, convert negative thoughts into positive, keeping diaries, setting goals, relapse prevention, nutrition and food issues, etc. The structure of the intervention and the materials used are described in detail in previous research (Zisi et al., 2016). At the end of each session, the individualized goals until the next meeting were set.

The counseling for physical activity enhancement was based on the basic principles of the theory of Goal Setting and its applications in the field of exercise (Locke \& Latham, 1990; Theodorakis, Hatzigeorgiadis, Chroni, \& Goudas, 2007). Initially, the physical activity of the participants was recorded using pedometers. The physical activity goals were set based on these indications and also the participants' habits (individual plan).

\section{Follow-Up}

After the completion of the intervention phase of the smoking cessation program, 3 monthly follow-up was held individually and there were also frequent telephone calls on a weekly basis for 6 months. The purpose of the follow-up was to obtain information about the situation of the participant, to provide support and help in anything needed and the ultimate goal was the consolidation of change and the relapse prevention.

\section{Instruments}

A structured interview was used in the first meeting with each participant, before the intervention, to record demographic data, smoking history and previews cessation attempts. A semi-structured interview was conducted at the end of the intervention to evaluate the effectiveness of individual counselling and al- 
so to identify the contributing factors. The interview was based on the following questions:

1) What helped you more in your effort to quit smoking?

2) What did you gain from this smoking cessation program?

3) What were the major obstacles in the effort to quit smoking?

4) What was your general attitude about smoking before the intervention and how it is now (overall dependency)?

5) What changes did you feel that there are in your thoughts, habits and feelings in relation to smoking after the intervention?

Pedometers $S W$-200 (Yamax) were used, at the beginning, in the middle and at the end of the program, mainly as means of motivation in increasing physical activity (Taylor, Everson-Hock, \& Ussher, 2010).

\section{Data analysis}

Data from the interviews were analyzed using the qualitative method of content analysis. To organize the data, the NVivo Software was used. The questions for the interview were used as the first order classification. The second order classification was created according to the participants' answers in the above questions.

\section{Results and Discussion}

\section{Current smoking status}

The purpose of this study was to investigate if and how the participation in the intervention program affects the smoking cessation process, and in general the change to a healthier and quality lifestyle. At the end of the program, as shown in Table 1, three of the participants (37.5\%) quit smoking. They were among the four heavier smokers participated in this study, and as it comes out from their current age and their years of smoking, they started this bad habit at the age of 15-18. One of these four heavy smokers achieved a significant reduction at the end of the intervention phase, but 9 months later, after completing the program, returned almost to the initial number of cigarettes. Four participants (50\%) achieved a significant reduction of the number of cigarettes smoked, and they turned to light smokers ( $<10$ cigarettes). These participants have also start smoking at the age of 15 - 18 and they were smoking for almost 30 years, since three of them were above 45 years old. Regarding the attendance rate, it is notable that none of the participants interrupted the program but all of them managed to attend all the sessions and to achieve more or less important goals that had been set.

In the initial assessment, all the participants, except one, said that they had tried to give up smoking in several ways and techniques. In the question, what helped in the past, $45.5 \%$ said nothing, and that was the main reason they were prompted to participate in an organized intervention. Taking into account that all the participants were smoking for many years (Mean years of smoking = 21.25) and they all were heavy smokers (Mean number of cigarettes before in- 
tervention $=18.37$ ), the above findings are in accordance with the notion that participants in organized programs are usually the heavy smokers (Raupach et al., 2008; Zhu et al., 2000), who used to smoke a lot for many years, and had experienced previous unsuccessful attempts before they achieve the smoking cessation (Eurobarometer, 2009; Zhou et al., 2009). In this program, the participants didn't use any tobacco substances or medication, because they wanted to develop their own strengths, to rely on themselves and activate their own skills. The results from the content analysis, regarding the questions about the intervention program are presented below:

What helped you more in your effort to quit smoking?

As presented in Table 2, all the participants $(n=8)$ answered that the meetings with the advisor were very helpful, while a large proportion of them $(n=6)$ emphasized the benefits of the discussions with the advisor. They reported that this process helped them cover needs such as expression, sharing emotions, contact and this was very supportive for them throughout the smoking cessation effort. They drew strength from the continuous contact with the advisor and the sessions and thus, they could continue their difficult effort, work and process what hindered them from quitting, share feelings etc. Singleton and Pope (2000) have also reported a link between smoking and emotional coverage and have stressed that smokers can get help to stop smoking if they seek for special assis-

Table 2. Results for the question "What helped you more in your effort to quit smoking". Raw data and categories.

\begin{tabular}{|c|c|c|}
\hline $2^{\text {nd }}$ order & $3^{\text {rd }}$ order & Quotations \\
\hline \multirow[t]{3}{*}{$\begin{array}{l}\text { Meetings with } \\
\text { the advisor }\end{array}$} & $(\mathrm{n}=8)$ & $\begin{array}{l}\text { "The meetings with the advisor were the most helpful part of the program. I felt that I } \\
\text { was not alone in the process, there was someone to accompany me in this effort, a place } \\
\text { where I could share everything" }\end{array}$ \\
\hline & Exercise $(n=2)$ & "The exercise, that entered in my life" \\
\hline & Discussion $(n=6)$ & $\begin{array}{l}\text { "The discussion with the advisor was the most useful thing. Through the conversation, I } \\
\text { realized things about myself" }\end{array}$ \\
\hline \multirow[t]{4}{*}{$\begin{array}{l}\text { The content of } \\
\text { the program }\end{array}$} & $\begin{array}{l}\text { Resistance-management } \\
\text { techniques }(\mathrm{n}=2)\end{array}$ & $\begin{array}{l}\text { "The techniques proposed in the program were the most useful of all. They helped me to } \\
\text { resist the temptation of tobacco" }\end{array}$ \\
\hline & Goal setting process $(n=2)$ & $\begin{array}{l}\text { "The daily program, the goals setting and the effort to find ways to achieve them were } \\
\text { very helpful" }\end{array}$ \\
\hline & Time management $(\mathrm{n}=2)$ & $\begin{array}{l}\text { "Organizing my time in the day, the daily program that I organized and followed helped } \\
\text { me very much in reducing the number of cigarettes that I smoked" }\end{array}$ \\
\hline & $\begin{array}{l}\text { Support from the advisor }(\mathrm{n}= \\
4)\end{array}$ & $\begin{array}{l}\text { "The most helpful part of the program was the continuous contact and support from the } \\
\text { advisor" }\end{array}$ \\
\hline \multirow[t]{3}{*}{ Function } & $\begin{array}{l}\text { Support from the environment } \\
\qquad(\mathrm{n}=2)\end{array}$ & $\begin{array}{l}\text { "It helped me a lot the support from my environment mainly, from my husband but also } \\
\text { from other people that had quit smoking and were standing close to me" }\end{array}$ \\
\hline & $\begin{array}{l}\text { Changing the way of thinking } \\
\qquad(\mathrm{n}=2)\end{array}$ & "The different way of thinking that I adopted through the program" \\
\hline & Commitment $(\mathrm{n}=1)$ & "The commitment to the program and to the advisor helped me a lot" \\
\hline $\begin{array}{l}\text { Example for the } \\
\text { others }\end{array}$ & $(\mathrm{n}=2)$ & $\begin{array}{l}\text { "I wanted to be a good example for my son and the model to make him also try and give } \\
\text { up smoking" }\end{array}$ \\
\hline
\end{tabular}


tance. Counselling seems to have an important contribution to the smoking cessation effort, acting as a mediator in reducing the perceived difficulty of quitting (McCarthy et al., 2010), while the lack of support has been reported as problematic for the smoking cessation effort and as a main cause of relapse (Zhou et al., 2009).

Two of the participants considered particularly helpful the process of finding ways to resist and manage the smoking desire. Alpert (2009) referred to the refusal skills as a key component of a plan to discontinue training. Several other researches (Osch et al., 2008; Riet, Ruiter, Werrij, \& De Vries, 2008; Velicer, DiClemente, Rossi, \& Proshaska, 1990), related the resistance to smoking temptations with successful quitting attempt and relapses avoidance.

Goal setting and commitment to the goals were reported to play an important role during the abstinence process $(\mathrm{n}=2)$, a common finding in other studies (Locke \& Latham, 1990; 2002; Theodorakis et al., 2007). Being a model for their children was a particularly mobilizing motive for some parents $(n=2)$, who thought that they might influence their children to enter the smoking cessation process. They considered their own effort as an indirect way to improve their children's health and this was a very important reason to keep on their smoking cessation effort.

The change of the way of thinking and hence the lifestyle change adopted through the program, was reported as the most important help $(n=2)$. The certain key objective of the intervention program helped them not only in the smoking abstinence effort, but also to begin to organize and achieve goals in other key areas of their lives. As Epstein, Griffin and Botvin (2000) mentioned, a program for the development of personal skills may play an important role in smoking cessation.

Only a few participants mentioned exercise $(n=2)$ and the auxiliary role it may play in the smoking cessation process, although this finding has been confirmed by numerous studies (i.e. Boudreaux et al., 2003; DeRuiter \& Faulkner, 2006; Everson-Hock, Taylor, \& Ussher, 2010; Kinnunen, Korhonen, Craft, \& Perna, 2010; Lujic, Reuter, \& Netter, 2005; Marcus et al., 2003; Paavola et al., 2001; Taylor et al., 2010; Taylor \& Katomeri, 2007; Ussher, West, McEwen, Taylor, \& Steptoe, 2003).

Finally, quite all the participants ( 7 out of 8 ) report the role of the support from both the advisor and their environment, as particularly helpful. Carlson, Taenzera, Koopmansa and Casebeer (2003) and Christakis and Fowler (2008), stressed the importance of the support from friends and family in the smoking cessation effort. Social support seems to play an important role in preserving smoking abstinence and increasing the rate of smoking cessation (Clarke \& Aish, 2002; Lawhon, Humfleet, Hall, Reus, \& Munoz, 2009; Manfredi, Cho, Crittenden, \& Dolecek, 2007). The survey of Hyland, Wakefield, Higbeel, Szczypka and Cummings (2006), demonstrates the importance of environmental modification, such as the restriction of smoking in the house, as a smoking cessation tool. 
Theodorakis (2010) underlines the important role of the environment, postulating that it can exert both positive and negative influence on the smoking cessation process, while Zhou et al. (2009) suggest that the environment is an important factor in preventing relapse. Finally Nichter, Nichter, Carkoglu and Lloyd-Richardson (2010) mentioned the protective role of friends throughout the smoking cessation effort. It seems that individual counseling based on motivational interviewing offers the necessary support that is of important help to give up smoking.

\section{What did you gain from this smoking cessation program?}

These questions were designed to identify the benefits of the program to be exploited and highly watched in future interventions. As shown in Table 3, the participants' answers were classified into four categories concerning the function and the aim of the program, and also the changes in their attitudes and feelings, forming the $2^{\text {nd }}$ order classification. There was also a $3^{\text {rd }}$ order classification of the answers within each of the above four categories.

In an effort to refine the function and their overall profit from this program, the participants indicated that the knowledge and the information $(n=4)$ they

Table 3. Results for the question "What did you gain from this smoking cessation program".

\begin{tabular}{|c|c|c|}
\hline $2^{\text {nd }}$ Order & $3^{\text {rd }}$ Order & Quotations \\
\hline \multirow{3}{*}{$\begin{array}{l}\text { Concerning the } \\
\text { function }\end{array}$} & $\begin{array}{l}\text { Knowledge Information } \\
\qquad(\mathrm{n}=4)\end{array}$ & $\begin{array}{l}\text { I gained a lot of knowledge about the harmful effects of smoking in my body, about } \\
\text { the smoking cessation process and general a lot of things that helped me in smoking } \\
\text { abstinence and cessation }\end{array}$ \\
\hline & Commitment $(\mathrm{n}=3)$ & $\begin{array}{l}\text { The commitment was something that helped me a lot during the program. My } \\
\text { participation in the program functions as a commitment both during the effort and } \\
\text { now that I have completed the program }\end{array}$ \\
\hline & Support $(\mathrm{n}=8)$ & $\begin{array}{l}\text { The support from the advisor. There was someone with whom I could discuss } \\
\text { everything, share everything and set goals. Having support in this way was the } \\
\text { biggest gain }\end{array}$ \\
\hline \multirow{3}{*}{$\begin{array}{l}\text { Concerning the } \\
\text { Goal }\end{array}$} & Smoking Cessation $(\mathrm{n}=3)$ & A life without tobacco. The most important thing that I won from the program \\
\hline & Smoking Reduction $(\mathrm{n}=4)$ & $\begin{array}{l}\text { I substantially reduced the number of cigarettes, which was the most important thing } \\
\text { for me }\end{array}$ \\
\hline & Resistance Techniques $(\mathrm{n}=1)$ & I learned how I can get control of the cigarette and how I can resist the temptation \\
\hline \multirow{5}{*}{$\begin{array}{l}\text { Concerning my } \\
\text { attitude }\end{array}$} & $\begin{array}{l}\text { Motivation Sensitization } \\
\qquad(\mathrm{n}=3)\end{array}$ & $\begin{array}{l}\text { Through the program I was motivated and committed to the effort of smoking } \\
\text { cessation. I am working constantly on the idea of quitting }\end{array}$ \\
\hline & Self-Confidence $(\mathrm{n}=5)$ & $\begin{array}{l}\text { I increased my self-confidence and believed more in myself and my strength. I know } \\
\text { what I can do, what I can manage, what is realistic and feasible }\end{array}$ \\
\hline & Self-Knowledge $(\mathrm{n}=4)$ & $\begin{array}{l}\text { I saw, I learned and knew more things not only for myself as what I can do, what I } \\
\text { can bear, but also about my relationship with the cigarette, what is for me a cigarette, } \\
\text { what gives me why I use and now I try to derive all of them in healthier ways. }\end{array}$ \\
\hline & Basis $(\mathrm{n}=1)$ & After the program I felt that I have a basis in what is called quit attempt \\
\hline & Safety $(\mathrm{n}=1)$ & $\begin{array}{l}\text { The program made me feel more confident about myself, about my skills for my } \\
\text { efforts in general }\end{array}$ \\
\hline \multirow{2}{*}{$\begin{array}{l}\text { Concerning the } \\
\text { feelings }\end{array}$} & Stress Reduction $(\mathrm{n}=1)$ & I am not anxious and worry about smoking as I was in the past \\
\hline & Calm Relaxation $(\mathrm{n}=2)$ & I am generally calmer, more relaxed, less strict with the children \\
\hline
\end{tabular}


got about smoking and related issues, and also about the smoking cessation process, which mobilized them to give up smoking and preserve smoking abstinence. Several researchers are focusing on the cognitive part as a mean to identify the benefits and losses of smoking and non-smoking behavior (i.e. Theodorakis, 2010). It is considered important for a smoking cessation program to include information about the consequences of tobacco on health, and also about the social influences of smoking (Alpert, 2009). Besides, it seems that health concerns affect and increase preparedness to quit (Curry, Grothaus, \& McBride, 1997) and education of smokers, within the counselling framework, about the effects of passive smoking may have a positive contribution to the smoking cessation process (Schane et al., 2013).

All the participants said that the most significant gain for them was that they achieved their goals related either to smoking cessation $(n=3)$, or to smoking reduction $(n=4)$. The development of techniques for the management of smoking desire $(\mathrm{n}=1)$ was also considered as an important goal. Quite all the participants were talking about changes regarding their attitudes. They mentioned as particularly significant the benefits in personal characteristics, such as increased insight and self-knowledge $(n=5)$, which helped them to understand their behavior, without any pressure from the advisor, since the lack of pressure is a basic principle of motivational interviewing. They also mentioned that their self-confidence was increased $(n=5)$ and this made them feel stronger and more confident about their effort to achieve their goals. Increased self-efficacy motivated them in the pursuit of their goals $(n=3)$ and as it has been reported in other studies, it effectively contributed to the effort of smoking cessation (Prochaska, 1996; Prochaska, Velicer, Guadagnoli, Rossi, \& Di Clemente, 1991; Osch et al., 2008; Riet et al., 2008; Velicer et al., 1990). All the above findings provide evidence for the auxiliary and effective role of the motivational interviewing used in the current intervention study, an important principle of which is to support the self-efficacy, in order to increase the chances of achieving change. Participants also reported that within the program they felt secure $(\mathrm{n}=$ $1)$, having a base $(n=1)$, a feeling of confidence that was particularly helpful throughout all this cessation effort, findings that confirm the basic principles of motivational interviewing, that is to increase the participant's faith in his own capabilities in order to overcome the obstacles and achieve the change. Bandura (1997) was the first to mention the important role of a cognitive mechanism, self-efficacy as a mediator in the process of behavior change. He described it as a situation in which the individual is self-confident about his abilities to face risky situations without any relapse. Self-efficacy has been proved an important determinant of change in several health behaviors affecting the choices, the effort, the persistence, the time allocated in the effort for change, anxiety and stress managing techniques (Bandura, 1997). Self-efficacy is also functioning as a motivational factor affecting feelings and behavior (Bandura, 1997) and increases gradually following the individuals' progress through the 5 stages of behavior 
change.

Several participants reported emotional gains referring to the reduction of stress and concerns $(n=1)$ and ensuring greater calm and relaxation $(n=2)$. Stress management, in various ways, has been the topic of numerous studies in the field of smoking cessation and it has been found that anxiety and stress play an important role in the reinforcement of smoking behavior (Nosen \& Woody, 2009), since stress relief is usually mentioned as a main motive to smoke (Curry, Grothaus, McAfee, \& Pabiniak, 1998; Graham et al., 2008) and thus a barrier in quitting smoking (Aubin et al., 2010; Hughes, 2009). It has been stated that intervention programs aiming in stress management are more likely to be successful (Zhu et al., 1996). It seems that the reduction of stress and anxiety through an intervention program is not just a personal benefit but also an important tool in increasing the chances of a successful quitting attempt.

What were the major obstacles in the effort to quit smoking?

These questions were aiming on identifying the most serious obstacles in the smoking cessation process, so that to study how they could be handled effectively and develop strategies and practices for future use and improvement of the current intervention program.

As shown in Table 4, the participants reported as key problems-obstacles in giving up smoking and maintaining abstinence from smoking, the difficult situations $(\mathrm{n}=5)$, which pushed them to seek help and consolation in cigarette, a finding common in other studies (i.e. Aubin et al., 2010; Curry et al., 1998; Hughes, 2009; Nosen \& Woody, 2009). An important obstacle was also reported to be the lack of support from the community-supportive environment, not only in the sense of a lack of support and faith in their attempt $(n=2)$, but also as a

Table 4. Results for the question "What were the major obstacles in the effort to quit smoking".

\begin{tabular}{|c|c|}
\hline $2^{\text {nd }}$ Order & Quotations \\
\hline $\begin{array}{l}\text { Difficult situations-stress } \\
\qquad(\mathrm{n}=5)\end{array}$ & $\begin{array}{l}\text { I faced Family issues which made it difficult to work and mainly to assemble, maintain calm and stress } \\
\text { management }\end{array}$ \\
\hline $\begin{array}{l}\text { Pressure from the family } \\
\text { environment }(n=2)\end{array}$ & Lack of support from the family environment \\
\hline Friends $(n=2)$ & $\begin{array}{l}\text { All my friends are smokers, which particularly complicate my efforts. I felt that I had no allies, someone to } \\
\text { speak at a difficult time and will understand me }\end{array}$ \\
\hline Habit $(n=1)$ & I thought I could not change anything (concerning the habit), but I realized that I could and it happened \\
\hline Addiction $(\mathrm{n}=1)$ & Addiction. I felt totally addicted to smoking. Withdrawal symptoms caused by nicotine \\
\hline Myself $(n=2)$ & Myself. My weakness as a personality trait made it difficult. $1 \mathrm{~m}$ not as strong character \\
\hline Nothing $(n=2)$ & $\begin{array}{l}\text { I didn't face any major obstacle in my effort to quit smoking. With the help of the program I feel able to } \\
\text { manage every difficulty in my effort. }\end{array}$ \\
\hline My job $(n=1)$ & The stress of work which I tried to manage with the use of cigarette, as I had learned \\
\hline $\begin{array}{l}\text { The idea of consistent } \\
\text { cessation }(n=1)\end{array}$ & I got panic at the thought that I will never again smoke not even one cigarette \\
\hline
\end{tabular}


failure influence attempt $(\mathrm{n}=2)$ by offering them a cigarette, commenting their effort, smoking in front of them and other similar actions. Dealing with difficult situations and the lack of support from the environment are two very important factors to divert and throw the smokers from their cessation effort, by reducing their concentration and their energy, causing stress and unhappiness, a finding reported in previous research (Christakis \& Flower, 2008; Clarke \& Aish, 2002; Hyland et al., 2006; Lawhon et al., 2009; Nichter et al., 2010; Zhou et al., 2009).

Single cases referred to other obstacles that made the abstinence from smoking difficult, such as addiction and dependence $(n=1)$ an obstacle also mentioned by Hughes (2009) as finding. The participants also referred as obstacles, the place and nature of work $(n=1)$, personality traits $(n=1)$ and the idea of smoking cessation per se $(n=1)$ as well. It is worth mentioning that the participants' reports from the individual counselling sessions, present a significant change in the specific manner and intensity that they were talking about the difficulties and the possible obstacles they faced along the way of the intervention. The main difference lay in the size of the obstacles and whether they believed that they can manage and overcome them. Characteristically, as the participants reported during the counseling sessions, at the beginning they referred to arising obstacles that may cost even the interruption of their cessation effort, however after the intervention, they believed that they can successfully face all these difficulties. A notable answer of two participants, at the end of the program, was that there was no difficulty and no obstacle to stop trying. It seems that the participation in the program resulted in changes at a personal level, such as increased insight, self-efficacy and self-confidence, that fostered trust in themselves and the confidence that they can manage any difficulty. Besides, that was the main goal of motivational interviewing; to increase participants' faith by consulting the forces that should manage to overcome the obstacles and achieve the change.

What was your general attitude about smoking before the intervention and how it is now (overall dependency)?

These questions were designed to identify the differences that may have occurred in the general behavior on smoking because of the participation in the smoking cessation program. Table 5 shows the classification of responses as the participants remember before and as they see it after the intervention.

Noteworthy are the results about the overall change through participation in the intervention program. Most participants $(\mathrm{n}=7)$ are talking about the absolute dependence and the lack of control $(n=5)$ in smoking behavior that they experienced before the participation in the program. They said that they would do anything for a cigarette, that they smoked without any control and that often "caught" themselves to smoke more than one cigarette at the same time or that they found themselves with a cigarette in hand without remembering how and when entered in this process, but now they consciously control their smoking behavior. Almost all participants said that, after the intervention they are more 
Table 5. Results for the question "What was your overall attitude about smoking before the intervention and how it is now (overall dependency)".

\begin{tabular}{|c|c|c|}
\hline $2^{\text {nd }}$ Order & $3^{\text {rd }}$ Order & Quotations \\
\hline \multirow[b]{2}{*}{ Before } & $\begin{array}{l}\text { Totally addicted } \\
\qquad(\mathrm{n}=7)\end{array}$ & $\begin{array}{l}\text { I felt very dependent, stuck with smoking. I would do anything, I would leave even my small } \\
\text { children alone to go to smoke. Each activity before was related and combined with smoking }\end{array}$ \\
\hline & $\begin{array}{l}\text { Lack of control } \\
\qquad(\mathrm{n}=5)\end{array}$ & $\begin{array}{l}\text { Before the intervention, I smoked without control. I was neither thinking how much I am } \\
\text { smoking nor if I want to smoke. I was with several lighted cigarettes on my hand without } \\
\text { realizing it }\end{array}$ \\
\hline \multirow[b]{2}{*}{ After } & $\begin{array}{l}\text { More independent } \\
\qquad(\mathrm{n}=6)\end{array}$ & $\begin{array}{l}\text { Now I feel more independent, more liberated, more free. Now I have no worries about doing } \\
\text { everything to find a cigarette and not all of my movements, actions, activities, behavior are } \\
\text { linked with smoking }\end{array}$ \\
\hline & More control $(n=6)$ & $\begin{array}{l}\text { After the intervention, I feel I have more control. I managed to reach at } 8 \text { cigarettes and } \\
\text { generally to control them. I feel good with those } 8 \text { and do not want to go further. Now I realize } \\
\text { how many cigarettes I smoked. If and when I want to smoke now is a conscious choice and } \\
\text { not automated movement }\end{array}$ \\
\hline
\end{tabular}

independent $(\mathrm{n}=6)$, freer, do not feel cigarette's captive and they can decide when and whether to smoke a cigarette. They talk about a completely conscious control of their condition $(n=6)$. Even those who have not ceased smoking, they said that they can choose when they want to smoke and if they really want it.

The control of smoking behavior is very important in the cessation process, as it affects both the intention and the quit attempt (Kovač, Rise, \& Moan, 2009). The important role of control emerges and through the theory of Planned Behavior (TPB, Ajzen, 1985), which is used to bring out the factors linked with the adoption of health behaviors (Fishbein \& Ajzen, 2005). According to TPB, the main factor that provides the behavior is the intention, which is determined by the attitudes, subjective norms, and control of behavior. In order to change a person's behavior as a smoker, he should be affected emotionally, cognitively, to believe that things are controlled by him and to also receive help and support from significant others. Therefore, the gain of better control achieved through the current intervention is very important, not only in achieving the behavior change that is smoking abstinence, but also in maintaining this behavior and achieving cessation.

What changes did you feel that there are in your thoughts, habits and feelings in relation to smoking after the intervention?

These questions focused on the changes in thoughts and feelings as a result of the participation in the smoking cessation program. As shown in Table 6, the participants' answers were classified into three categories concerning the changes in thoughts, feelings and habits, forming the $2^{\text {nd }}$ order classification. There was also a $3^{\text {rd }}$ order classification of the answers within each of the above three categories.

Several of the participants reported, as a result of the intervention, changes in their thoughts, which has been found to play an important role in smoking cessation (Nosen \& Woody, 2009). More specifically, they talk about more conscious thought $(\mathrm{n}=8)$, something that has to do with awareness, which accord- 
Table 6. Results for the question "What changes did you feel that there are in your thoughts, habits and feelings in relation to smoking after the intervention".

\begin{tabular}{|c|c|c|}
\hline $2^{\text {nd }}$ Order & $3^{\text {rd. }}$ Order & Quotations \\
\hline \multirow{6}{*}{ Thoughts } & Negative thoughts $(n=2)$ & $\begin{array}{l}\text { I have only negative thoughts for the cigarette that I didn't have before. I always think } \\
\text { it's something bad }\end{array}$ \\
\hline & Controlling thoughts $(\mathrm{n}=2)$ & $\begin{array}{l}\text { The most fundamental change is at thinking level. Now I have the control of cigarette } \\
\text { and thought about it and it does not control me }\end{array}$ \\
\hline & Positive thoughts $(\mathrm{n}=2)$ & I make positive and optimistic thoughts for a life without cigarette \\
\hline & Think more $(\mathrm{n}=2)$ & I am thinking much more about smoking and when I smoke I feel bad \\
\hline & Think less $(\mathrm{n}=1)$ & I don't think about cigarette. I do not care at all \\
\hline & Conscious thought $(\mathrm{n}=8)$ & I realized how I use the cigarette. What is it about me, what gives me what deprives me \\
\hline \multirow{7}{*}{ Feelings } & Guilt $(\mathrm{n}=1)$ & I feel remorse and guilt and because I continue smoking. I feel like dirt on me \\
\hline & Satisfaction $(\mathrm{n}=4)$ & $\begin{array}{l}\text { I hated dependence and wanted somehow to stop there. I feel very satisfied, full and } \\
\text { won that got away from this dependence }\end{array}$ \\
\hline & Calm $(n=1)$ & I feel more relaxed and calm \\
\hline & Liveliness $(\mathrm{n}=1)$ & I live intensely, with more vitality \\
\hline & Happiness $(\mathrm{n}=2)$ & I feel happier, more joyful \\
\hline & Pride $(\mathrm{n}=7)$ & I feel particularly proud of myself which I needed \\
\hline & Freedom $(\mathrm{n}=3)$ & I feel free \\
\hline \multirow{4}{*}{ Habits } & Thought control $(\mathrm{n}=8)$ & $\begin{array}{l}\text { "The most important change for me is that I learned to control my cigarette and not } \\
\text { what me }\end{array}$ \\
\hline & $\begin{array}{l}\text { Changing Habits linked to } \\
\text { smoking }(\mathrm{n}=8)\end{array}$ & $\begin{array}{l}\text { "I have changed considerably habits and behaviors at different levels. One of the most } \\
\text { important for me is that I got up early in the morning to catch to smoke. Now I do not } \\
\text { concern so much, I enjoy my sleep and get up more slowly without stress }\end{array}$ \\
\hline & Activities $(\mathrm{n}=4)$ & I engage in activities \\
\hline & Adopt a healthy lifestyle $(\mathrm{n}=8)$ & I live more healthily. I will keep trying \\
\hline
\end{tabular}

ing to the Motivational Interviewing model affects the relationship with smoking (Gemmell \& Di Clemente, 2009), and also with commitment and the way it affects the cessation process (Glanz, Rimer, \& Lewis, 2002; Kovač et al., 2009; Locke \& Latham, 1990; 2002; Musich, Chapman, \& Ozminkowski, 2009). Yet, they talk about an increase in positive thinking $(n=2)$ concerning the health benefits associated with discontinuation and adopting a more negative thinking against smoking and the consequences $(\mathrm{n}=2)$, findings that have also been reported in other studies (Alpert, 2009; Curry et al., 1997; Schane et al., 2013; Theodorakis, 2010). It seems that the participants carried out, through the intervention, significant changes in their decisional balance regarding smoking behavior. The decisional balance, proposed by Janis and Mann (1977), reflects the ability of someone to balance the advantages and disadvantages of changing a behavior. While the participants initially believed, that the advantages of the "problematic behavior" were superior than the disadvantages, after the intervention they believe that the disadvantages far outweigh the advantages, which also confirms the step change according to the Transtheoretical Model (Miller \& Rollnick, 2002). At the stage of activation and maintenance of this model, the 
disadvantages outweigh the advantages. Finally, two participants reported that the most important changes regarded the control of their thinking, two other reported that they are not thinking smoking at all and another one reported that is thinking much more anymore whatever has to do with smoking cessation.

Several of the participants' reports concern changes in emotions, which is a finding also supported by other studies. Shahab and West (2009) found in their study significant positive emotional change after cessation, focusing mainly on self-gratification and self-vindication. Musich et al. (2009) argued that emotions are directly related to the intention to give up smoking, even more than behaviors. According to the findings of the present study, the participants reported that they feel more relaxed and calm $(n=1)$, a finding that may be associated with improvements in stress management (McCarthy et al., 2010). Two participants reported that they feel happier $(\mathrm{n}=2)$, a finding that simulates the findings of Shahab and West (2009). One of the participants also said that after changing his smoking behavior, he feels more alive and more active $(\mathrm{n}=1)$, something that may be related to physical changes (Everson-Hock, Taylor, Ussher, \& Faulkner, 2010). The majority of the participants $(n=8)$ said that they feel happier, with increased confidence, and having much gained, feelings that might be present after achieving their goals (Locke \& Latham, 2002; 1990; Theodorakis et al., 2007). Several participants said that they feel more free and independent $(\mathrm{n}=3)$, which may be linked to their increased confidence and belief that they can succeed on their own. Besides, increased confidence has been found to lead to successful cessation (Manfredi et al., 2007). Finally, those who have achieved their goal of reduction or cessation $(n=7)$ said that they feel proud of their achievement, while the person who failed to achieve a change indicated that he is feeling remorse and guilt that continues to smoke $(n=1)$.

Regarding the habits, all the participants admitted that they changed many of their daily habits that was combined with smoking $(n=8)$. According to Theodorakis and Papaioannou (2002), this change is necessary in such efforts since the adoption of healthy behaviours is associated with avoiding negative behaviours. It is also noteworthy that all the participants said that they got the control of smoking $(\mathrm{n}=8)$, a finding that in previous studies (Butler, 2001; Kovač et al., 2009) is also one of the major benefits, because it is directly related to increased confidence, self-efficacy and positive feelings, factors that are directly associated with increased chances of a successful cessation. All of the participants said they have adopted a healthier lifestyle $(\mathrm{n}=8)$, while half of them showed increased activity $(\mathrm{n}=4)$, a finding that is probably attributed to the opening and engagement in new activities as an alternative to smoking (Alpert, 2009; Davis et al., 1994).

\section{Conclusion}

According to the findings of the present study, the intervention program that was based on Motivational Interviewing, helped the participants in the process 
of abstinence and smoking cessation. All of the participants completed the program and achieved important goals such as smoking cessation, smoking reduction, physical activity increasement, knowledge enhancement, personal skills development. They all changed their lifestyle and their way of thinking by adopting an overall healthier and more quality lifestyle. Although the number of the participants is quite small to generalize the findings of the current study, it is worth mentioning that none of the participants completed the program without having made a change to one of the basic areas of the program such as reduction or smoking cessation, adoption of exercise behavior, stress management, time management, development of personal skills and generally adopting an overall healthier and quality lifestyle. After the intervention, all the participants said that they felt they gained control over the cigarette and that they feel more independent and could now rely on their own forces. It is very important that all the participants, either they succeeded in quitting smoking or not, began seeing themselves as future nonsmokers. Those who quitted were confident that they can maintain the smoking cessation while those who didn't quit believe that they have the knowledge, skills, strength and everything else required for quitting. They were much more confident about themselves with increased self-efficacy and confidence, which also confirms the effectiveness of motivational interviewing in the present intervention.

A main difficulty in the present intervention was to mobilize people to participate in some kind of physical activity and to adopt exercise as a lifestyle habit. The program did not involve systematic participation in any kind of exercise over time. Physical activity was used mainly as a way of managing the desire only, and not as a health behavior change, thus it was not meant to last over time. Taking into account the difficulty of mobilizing the participants in the adoption of exercise habits integrated in their lifestyle over time, the next step should be an intervention program that includes the combination of individual counselling for smoking cessation from mental health specialists and individual counselling for exercise from exercise specialists with training in counselling so as to constitute a more integrated counselling model for changing habits and health behaviors to a more quality lifestyle. Although a smoking cessation process is quite individualized, a large scale trial should help to shed more light in the effectiveness of Motivational Interviewing techniques in this process, especially in interventions that involve Physical Activity enhancement.

\section{References}

Ajzen, I. (1985). From Intentions to Actions: A Theory of Planned Behavior. In J. Kuhl, \& J. Beckman (Eds.), Action-Control: From Cognition to Behavior (pp. 11-39). Heidelberg: Springer. https://doi.org/10.1007/978-3-642-69746-3_2

Alpert, P. (2009). Smoking Cessation: Difficult But Not Impossible. Home Health Care Management Practice, 21, 281-283. https://doi.org/10.1177/1084822308329256

Aubin, H. J., Peiffer, G., Delbarre, A., Vicaut, E., Jeanpetit, Y., Solesse, A. et al. (2010). The French Observational Cohort of Usual Smokers (FOCUS) Cohort: French Smokers 
Perceptions and Attitudes towards Smoking Cessation. BMC Public Health, 10, 100-107. https://doi.org/10.1186/1471-2458-10-100

Bandura, A. (1997). Self-Efficacy. The Exercise of Control. New York: W.H. Freeman and Company. https://doi.org/10.1016/S0091-7435(02)00048-8

Boudreaux, E., Francis, J., Taylor, C., Scarinci, I., \& Brantley, P. (2003). Changing Multiple Health Behaviours: Smoking and Exercise. Preventive Medicine, 36, 471-478.

Butler, C. C., Rolnick, S., Cohen, D., Russel, I., Bachmann, M., \& Stott, N. (1999). Motivational Consulting versus Brief Advice for Smokers in General Practice: A Randomized Trial. British Journal of General Practice, 49, 611-616.

Butler, J. T. (2001). Principles of Health Education and Health Promotion (3rd ed.). Englewood, Clorado: Morton.

Carlson, L. E., Taenzera, P., Koopmansa, I., \& Casebeer, A. (2003). Predictive Value of Aspects of the Transtheoretical Model on Smoking Cessation in a Community-Based, Large-Group Cognitive Behavioral Program. Addictive Behaviors, 28, 725-740. https://doi.org/10.1016/S0306-4603(01)00268-4

Christakis, N. A., \& Fowler, J. H. (2008). The Collective Dynamics of Smoking in a Large Social Network. New England Journal of Medicine, 358, 2249-2258. https://doi.org/10.1056/NEJMsa0706154

Clarke, K. E., \& Aish, A. (2002). An Exploration of Health Beliefs and Attitudes of Smokers with Vascular Disease Who Participate in or Decline a Smoking Cessation Program. Journal of Vascular Nursing, 20, 96-105.

https://doi.org/10.1067/mvn.2002.127735

Colby, S. M., Monti, P. M., Barnett, N. P., Rohsenow, D. J., Weissman, K., Spirito, A. et al. (1998). Brief Motivational Interviewing in a Hospital Setting for Adolescent Smoking: A Preliminary Study. Journal of Consulting and Clinical Psychology, 66, 574-578. https://doi.org/10.1037/0022-006X.66.3.574

Colby, S. M., Monti, P. M., Tevyaw, T. O., Barnett, N. P., Spirito, A., Rohsenow, D. J. et al. (2005). Brief Motivational Intervention for Adolescent Smokers in Medical Settings. Addictive Behaviors, 30, 865-874. https://doi.org/10.1016/j.addbeh.2004.10.001

Curry, S. J., Grothaus, I. X., \& McBride, C. (1997). Reasons for Quitting: Intrinsic and Extrinsic Motivation for Smoking Cessation in a Population-Based Sample of Smokers. Addictive Behaviors, 22, 727-739. https://doi.org/10.1016/S0306-4603(97)00059-2

Curry, S. J., Grothaus, L. C., McAfee, T., \& Pabiniak, C. (1998). Use and Cost Effectiveness of Smoking-Cessation Services under Four Insurance Plans in a Health Maintenance Organization. New England Journal of Medicine, 339, 673-679. https://doi.org/10.1056/NEJM199809033391006

Davis, M. A., Neuhaus, J. M., Moritz, D. J., Lein, D., Barklay, J. D., \& Murphy, S. P. (1994). Health Behaviours and Survival among Middle-Aged and Older Men and Women in the NHANES I Epidemiologic Follow-Up Study. Preventive Medicine, 23, 369-376. https://doi.org/10.1006/pmed.1994.1051

DeRuiter, W., \& Faulkner, G. (2006). Tobacco Harm Reduction Strategies: The Case for Physical activity. Nicotine \& Tobacco Research, 8, 157-168. https://doi.org/10.1080/14622200500494823

Dunn, C., Deroo, L., \& Rivara, F. P. (2001). The Use of Brief Interventions Adapted from Motivational Interviewing across Behavioral Domains: A Systematic Review. Addiction, 96, 1725-1742. https://doi.org/10.1046/j.1360-0443.2001.961217253.x

Epstein, J. A., Griffin, K. W., \& Botvin, G. J. (2000). Competence Skills Help Deter Smoking among Inner City Adolescents. Tobacco Control, 9, 33-39. 
https://doi.org/10.1136/tc.9.1.33

Erol, S., \& Erdogan, S. (2008). Application of a Stage Based Motivational Interviewing Approach to Adolescent Smoking Cessation: The Transtheoretical Model-Based Study. Patient Education and Counseling, 72, 42-48. https://doi.org/10.1016/j.pec.2008.01.011

Eurobarometer (2009). Tobacco, Special Eurobarometer 332. Brussels: European Commission, TNS Opinion \& Social.

Everson-Hock, E. S., Taylor, A. H., \& Ussher, M. (2010). Readiness to Use Physical Activity as a Smoking Cessation Aid: A Multiple Behaviour Change Application of the Transtheoretical Model among Quitters Attending Stop Smoking Clinics. Patient Education and Counseling, 79, 156-159. https://doi.org/10.1016/j.pec.2009.09.016

Everson-Hock, E. S., Taylor, A. H., Ussher, M., \& Faulkner, G. (2010). A Qualitative Perspective on Multiple Health Behaviour Change: Views of Smoking Cessation Advisors Who Promote Physical Activity. Journal of Smoking Cessation, 5, 7-14. https://doi.org/10.1375/jsc.5.1.7

Fishbein, M., \& Ajzen, I. (2005). Theory-Based Behavior Change Interventions: Comments on Hobbis and Sutton. Journal of Health Psychology, 10, 27-31.

https://doi.org/10.1177/1359105305048552

Garvey, A. J., Kalman, D., Hoskinson, R. J., Kinnunen, T., Wadler, B. M., Thomson, C. C., \& Rosner, B. (2012). Front-Loaded versus Weekly Counseling for Treatment of Tobacco Addiction. Nicotine \& Tobacco Research, 14, 578-585.

https://doi.org/10.1093/ntr/ntr256

Gemmell, L., \& DiClemente, C. C. (2009). Styles of Physician Advice about Smoking Cessation in College Students. Journal of American College Health, 58, 113-119.

https://doi.org/10.1080/07448480903221251

Glanz, K., Rimer, B. K., \& Lewis, F. M. (2002). Health Behavior and Health Education. San Francisco: John Wiley \& Sons.

Godin, G. (1989). The Effectiveness of Interventions in Modifying Behavioral Risk Factors of Individuals with Coronary Heart Disease. Journal of Cardiopulmonary Rehabilitation and Prevention, 9, 223-236. https://doi.org/10.1097/00008483-198906000-00001

Gonseth, S., Abarca, M., Madrid, C., \& Cornuz, J. (2010) A Pilot Study Combining Individual-Based Smoking Cessation Counselling, Pharmacotherapy, and Dental Hygiene Intervention. BMC Public Health, 10, 348-352.

https://doi.org/10.1186/1471-2458-10-348

Graham, A. L., Papandonatos, G. D., DePue, J. D., Pinto, B. M., Borrelli, B., Neighbors, C. J. et al. (2008). Lifetime Characteristics of Participants and Non-Participants in a Smoking Cessation Trial: Implications for External Validity and Public Health Impact. Annals of Behavioral Medicine, 35, 295-307. https://doi.org/10.1007/s12160-008-9031-1

Hall, S. M., Humfleet, G. L., Muñoz, R. F., Reus, V. I., Prochaska, J. J., \& Robbins, J. A. (2011). Using Extended Cognitive Behavioral Treatment and Medication to Treat Dependent Smokers. American Journal Public Health, 101, 2349-2356. https://doi.org/10.2105/AJPH.2010.300084

Hassandra, M., Goudas, M., \& Theodorakis, Y. (2015). Exercise and Smoking: A Literature Overview. Health, 7, 1477-1491. https://doi.org/10.4236/health.2015.711162

Hennrikus, D. J., Lando, H. A., McCarty, M. C., Klevan, D., Holtan, N., Huebsch, J. A. et al. (2005). The TEAM Project: The Effectiveness of Smoking Cessation Intervention with Hospital Patients. Preventive Medicine, 40, 249-258. 
https://doi.org/10.1016/j.ypmed.2004.05.030

Hjalmarson, A., \& Boethius, G. (2007). The Effectiveness of Brief Advice and Extended Smoking Cessation Counseling Programs When Implemented Routinely in Hospitals. Preventive Medicine, 45, 202-207. https://doi.org/10.1016/j.ypmed.2007.06.014

Hughes, J. R. (2009). Smokers' Beliefs about the Inability to Stop Smoking. Addictive Behaviors, 34, 1005-1009. https://doi.org/10.1016/j.addbeh.2009.06.013

Hunt, Y., Rash, C. J., Burke, R. S., \& Parker, J. (2010). Smoking Cessation in Recovery: Comparing 2 Different Cognitive Behavioral Treatments. Addictive Disorders \& Their Treatment, 9, 64-74. https://doi.org/10.1097/ADT.0b013e3181bf0310

Hyland, A., Wakefield, M., Higbee1, C., Szczypka, G., \& Cummings, K. M. (2006). Anti-Tobacco Television Advertising and Indicators of Smoking Cessation in Adults: A Cohort Study. Health Education Research Theory \& Practice, 21, 348-354. https://doi.org/10.1093/her/cyl048

Janis, I. L., \& Mann, L. (1977). Decision Making: A Psychological Analysis of Conflict, Choice and Commitment. New York: Free Press.

Johnston, D. W., Johnston, M., Pollard, B., Kinmonth, A. L., \& Mant, D. (2004). Motivation Is Not Enough: Prediction of Risk Behaviour Following Diagnosis of Coronary Heart Disease from the Theory of Planned Behaviour. Health Psychology, 23, 533-538. https://doi.org/10.1037/0278-6133.23.5.533

Kinnunen, T. H., Korhonen, T., Craft, L. L., \& Perna, F. M. (2010). Treating Tobacco Dependence in Women with Exercise: Review on Effectiveness and Mechanisms. International Journal of Sport and Exercise Psychology, 8, 48-60.

https://doi.org/10.1080/1612197X.2010.9671933

Kovač, V. B., Rise, J., \& Moan, I. S. (2009). From Intentions to Quit to the Actual Quitting Process: The Case of Smoking Behaviour in Light of the TPB. Journal of Applied Biobehavioral Research, 14, 181-197. https://doi.org/10.1111/j.1751-9861.2010.00048.x

Lawhon, D., Humfleet, G. L., Hall, S. M., Reus, V. I., \& Munoz, R. F. (2009). Longitudinal Analysis of Abstinence-Specific Social Support and Smoking Cessation. Health Psychology, 28, 465-472. https://doi.org/10.1037/a0015206

Locke, E. A., \& Latham, G. P. (2002). Building a Practically Useful Theory of Goal Setting and Task Motivation: A 35-Year Odyssey. American Psychologist, 57, 705-717. https://doi.org/10.1037/0003-066X.57.9.705

Locke, E., \& Latham, C. (1990). A Theory of Goal Setting and Task Performance. Englewood Cliffs: Prentice Hall.

Lujic, C., Reuter, M., \& Netter, P. (2005). Psychological Theories of Smoking and Smoking Motivation. European Psychologist, 10, 1-24.

https://doi.org/10.1027/1016-9040.10.1.1

Manfredi, C., Cho, Y. I., Crittenden, K. S., \& Dolecek, T. A. (2007). A Path Model of Smoking Cessation in Women Smokers of Low Socio-Economic Status. Health Education Research, 22, 747-756. https://doi.org/10.1093/her/cyl155

Marcus, B., Albrecht, A., Lewis, B., Parisi, A., Hogan, J., King, T. et al. (2003). Rationale, Design, and Baseline Data for Commit to Quit II: An Evaluation of the Efficacy of Moderate-Intensity Physical Activity as an Aid to Smoking Cessation in Women. Preventive Medicine, 36, 479-492. https://doi.org/10.1016/S0091-7435(02)00051-8

Marti, B., Salonen, J., Tuomilehto, J., \& Pulska, P. (1988). Ten-Year Trends in Physical Activity in the Eastern Finnish Adult Population. Relationship to Socioeconomic and Lifestyle Characteristics. Acta Medica Scandinavica, 224, 195-203.

https://doi.org/10.1111/j.0954-6820.1988.tb19362.x 
McCarthy, D. E., Piasecki, T. M., Jorenby, D. E., Lawrence, D. L., Shiffman, S., \& Baker, T. B. (2010). A Multi-Level Analysis of Non-Significant Counseling Effects in a Randomized Smoking Cessation Trial. Addiction, 105, 2195-2208. https://doi.org/10.1111/j.1360-0443.2010.03089.x

McClure, J. B.., Ludman, E. J., Grothaus, L., Pabiniak, C., \& Richards, J. (2009). Impact of a Brief Motivational Smoking Intervention: The Get PHIT Randomized Controlled Trial. American Journal of Preventive Medicine, 37, 116-123. https://doi.org/10.1016/j.amepre.2009.03.018

Miller, W. R., \& Rollnick, S. (2002). Motivational Interviewing: Preparing People for Change (2nd ed.). New York, London: Guilford Press.

Musich, S., Chapman, L., \& Ozminkowski, R. (2009). Best Practices for Smoking Cessation: Implications for Employer-Based Programs. American Journal of Health Promotion, 24, 1-10. https://doi.org/10.4278/ajhp.24.1.TAHP

Nichter, M., Nichter, M., Carkoglu, A., \& Lloyd-Richardson, E. (2010). The Tobacco Etiology Research Network (TERN): Smoking and Drinking among College Students: "It's a Package Deal”. Drug and Alcohol Dependence, 106, 16-20. https://doi.org/10.1016/j.drugalcdep.2009.07.025

Norman, P., Conner, M., \& Bell, R. (1999). The Theory of Planned Behavior and Smoking Cessation. Health Psychology, 18, 89-94. https://doi.org/10.1037/0278-6133.18.1.89

Nosen, E. Z., \& Woody, S. (2009). Applying Lessons Learned from Obsessions: Metacognitive Processes in Smoking Cessation. Cognitive Therapy and Research, 33, 241-254. https://doi.org/10.1007/s10608-007-9180-8

Osch, L., Lechner, L., Reubsaet, A., Wigger, S., \& Vries, H. (2008). Relapse Prevention in a National Smoking Cessation Contest: Effects of Coping Planning. British Journal of Health Psychology, 13, 525-535. https://doi.org/10.1348/135910707X224504

Paavola, M., Vartianen, E., \& Puska, P. (2001). Smoking Cessation between Teenage Years and Adulthood. Health Education Research, 16, 49-57. https://doi.org/10.1093/her/16.1.49

Pisinger, C., Vestbo, J., Borch-Johnsen, K., Thomsen, T., \& Jorgensen, T. (2005). Acceptance of the Smoking Cessation Intervention in a Large Population-Based Study: The Inter99 Study. Scandinavian Journal of Public Health, 33, 138-145. https://doi.org/10.1080/14034940410028370

Prochaska, J. O. (1996). A Stage Paradigm for Intergrating Clinical and Public Health Approaches to Smoking Cessation. Addictive Behaviors, 21, 721-732. https://doi.org/10.1016/0306-4603(96)00031-7

Prochaska, J. O., \& DiClemente, C. C. (1983). The Stages and Processes of Self-Change in Smoking: Towards an Investigative Model of Change. Journal of Consulting and Clinical Psychology, 51, 390-395. https://doi.org/10.1037/0022-006X.51.3.390

Prochaska, J. O., Velicer, W. F., Guadagnoli, E., Rossi, J. S., \& Di Clemente, C. C. (1991). Patterns of Change: Dynamic Typology Applied to Smoking Cessation. Multivariate Behavioral Research, 26, 83-107. https://doi.org/10.1207/s15327906mbr2601_5

Raupach, T., Shahab, L., Neubert, K. et al. (2008). Implementing a Hospital-Based Smoking Cessation Program: Evidence for a Learning Effect. Patient Education and Counseling, 70, 199-204. https://doi.org/10.1016/j.pec.2007.10.005

Riet, J. V. T., Ruiter, R. A., Werrij, M. Q., \& De Vries, H. (2008). The Influence of Self-Efficacy on the Effects of Framed Health Messages. European Journal of Social Psychology, 38, 800-809. https://doi.org/10.1002/ejsp.496

Rigotti, N. A., Munafo, M. R., \& Stead, L. F. (2008). Smoking Cessation Interventions for 
Hospitalized Smokers: A Systematic Review. Archives of Internal Medicine, 168, 1950-1960. https://doi.org/10.1001/archinte.168.18.1950

Rigotti, N. A., Regan, S., Majchrzak, N. E., Knight, J. R., \& Wechsler, H. (2002). Tobacco use by Massachusetts Public College Students: Long Term Effect of the Massachusetts Tobacco Control Program. Tobacco Control, 11, 20-24.

Rollnick, S., \& Heather, N. (1992). Negotiating Behaviour Change in Medical Settings: The Development of Brief Motivational Interviewing. Journal of Mental Health, 1, 25-37. https://doi.org/10.3109/09638239209034509

Rollnick, S., \& Miller, W. R. (1995). What Is Motivational Interviewing? Behavioural and Cognitive Psychotherapy, 23, 325-334. https://doi.org/10.1017/S135246580001643X

Rollnick, S., Butler, C. C., \& Scott, N. (1997). Helping Smokers Make Decisions: The Enhancement of Brief Intervention for General Practice. Patient Education and Counseling, 31, 191-203. https://doi.org/10.1016/S0738-3991(97)01004-5

Rosenstock, I. M. (1974). Historical Origins of the Health Belief Model. Health Education Monographs, 2, 328-335. https://doi.org/10.1177/109019817400200403

Salonen, J., Slater, J., Tuomilehto, J., \& Raurama, R. (1988). Leisure Time and Occupational Physical Activity: Risk of Death from Ischemic Heart Disease. American Journal of Epidemiology, 127, 87-94. https://doi.org/10.1093/oxfordjournals.aje.a114794

Schane, R. E., Prochaska, J. J., \& Glantz, S. A. (2013). Counseling Nondaily Smokers about Secondhand Smoke as a Cessation Message: A Pilot Randomized Trial. Nicotine \& Tobacco Research, 15, 334-342. https://doi.org/10.1093/ntr/nts126

Shah, L. M., King, A. C., Basu, A., Krishnan, J. A., Borden, W. B., Meltzer, D. et al. (2010). Effect of Clinician Advice and Patient Preparedness to Quit on Subsequent Quit Attempts in Hospitalized Smokers. Journal of Hospital Medicine, 5, 26-32. https://doi.org/10.1002/jhm.536

Shah, Z. H., Rao, S., \& Mayo, H. G. (2008). What Are the Most Effective Ways You Can Help Patients Stop Smoking? The Journal of Family Practice, 57, 478-479.

Shahab, L., \& West, R. (2009). Do Ex Smokers Report Feeling Happier Following Cessation? Evidence from a Cross-Sectional Survey. Nicotine \& Tobacco Research, 11, 553-557. https://doi.org/10.1093/ntr/ntp031

Singleton, M. G., \& Pope, M. (2000). A Comparison of Successful Smoking Cessation Interventions for Adults and Adolescents. Journal of Counseling and Development, 78, 448-453. https://doi.org/10.1002/j.1556-6676.2000.tb01928.x

Taylor, A. H., \& Katomeri, M. (2007). Walking Reduces Cue-Elicited Cigarette Cravings and Withdrawal Symptoms, and Delays Smoking. Nicotine \& Tobacco Research, 9, 1183-1190. https://doi.org/10.1080/14622200701648896

Taylor, A. H., Everson-Hock, E. S., \& Ussher, M. (2010). Integrating the Promotion of Physical Activity within a Smoking Cessation Program: Findings from Collaborative Action Research in UK Stop Smoking Services. BMC Health Services Research, 10, 317. https://doi.org/10.1186/1472-6963-10-317

Theodorakis, Y. (2010). Exercise, Mental Health and Quality of Life. Thessaloniki: Christodoulidi.

Theodorakis, Y., \& Papaioannou, A. (2002). Student's Profile toward Healthy and Unhealthy Lifestyle, and Its Relationship to Sports. Psychology, 9, 547-562.

Theodorakis, Y., Hatzigeorgiadis, A., Chroni, S., \& Goudas, M. (2007). Goal Setting in Physical Education. In J. Liukkonnen, Y. VandenAuweele, B. Vereijken, D. Alferman, \& Y. Theodorakis (Eds.), Psychology for Physical Educators (pp. 21-34). Champaign, IL: Human Kinetics. 
Tuomilehto, J., Marti, B., Salonen, J., Virtala, E., Lahti, T., \& Puska, P. (1987). Leisure-Time Physical Activity Is Inversely Related to Risk Factors for Coronary Heart Disease in Middle-Aged Finnish Men. European Heart Journal, 8, 1047-1055.

https://doi.org/10.1093/oxfordjournals.eurheartj.a062169

Ussher, M., West, R., McEwen, A., Taylor, A., \& Steptoe, A. (2003). Efficacy of Exercise Counselling as an Aid to Smoking Cessation: A Randomised Controlled Trial. Addiction, 98, 523-532. https://doi.org/10.1046/j.1360-0443.2003.00346.x

Velicer, W. F., DiClemente, C. C., Rossi, J. S., \& Proshaska, J. O. (1990). Relapse Situations and Self-Efficacy: An Integrative Model. Addictive Behaviors, 15, 271-283. https://doi.org/10.1016/0306-4603(90)90070-E

World Health Organization (2015). International Statistical Classification of Diseases and Related Health Problems (10th revision, 5th ed.). Geneva: WHO.

World Health Organization and US National Cancer Institute (2016). The Economics of Tobacco and Tobacco Control. National Cancer Institute Tobacco Control Monograph 21. Geneva: World Health Organization.

Zhou, X., Nonnemaker, J., Sherrill, B., Gilsenan, A., Coste, F., \& West, R. (2009). Attempts to Quit Smoking and Relapse: Factors Associated with Success or Failure from the ATTEMPT Cohort Study. Addictive Behaviors, 34, 365-373.

https://doi.org/10.1016/j.addbeh.2008.11.013

Zhu, S. H., Melcer, T., Sun, J., Rosbrook, B., \& Pierce, J. P. (2000). Smoking Cessation with and without Assistance: A Population-Based Analysis. American Journal of Preventive Medicine, 18, 305-311. https://doi.org/10.1016/S0749-3797(00)00124-0

Zhu, S. H., Stretch, V., Balabanis, M., Rosbrook, B., Sadler, G., \& Pierce, J. P. (1996). Telephone Counseling for Smoking Cessation: Effects of Single-Session and Multiple-Session Interventions. Journal of Consulting and Clinical Psychology, 64, 202-211.

https://doi.org/10.1037/0022-006X.64.1.202

Zisi, V., Gratsani, S., Leontari, D., \& Theodorakis, Y. (2016). Combining Individual and Group Counselling Sessions in a Smoking Cessation Intervention. Psychology, 7, 1766-1784. https://doi.org/10.4236/psych.2016.714165 